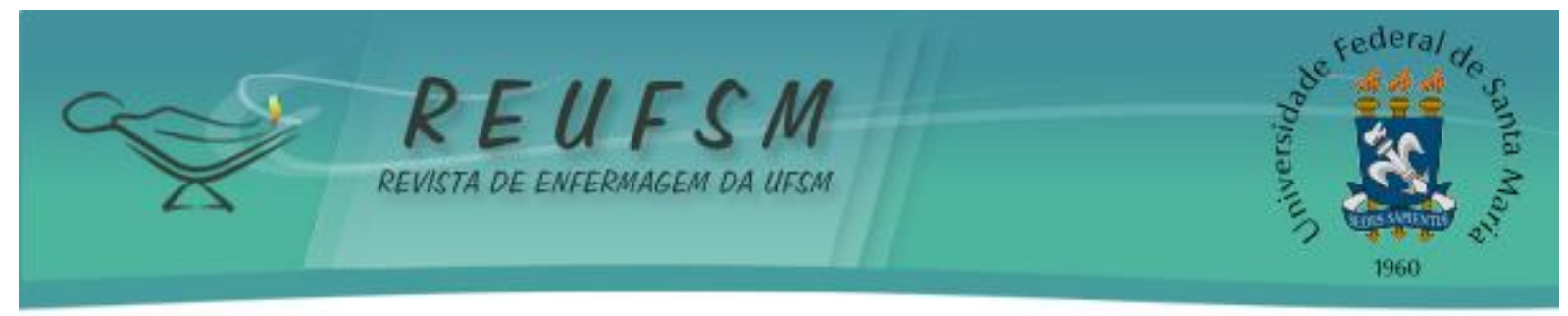

ARTIGO ORIGINAL

\title{
HISTÓRIAS DE CUIDADOS ENTRE IDOSOS INSTITUCIONALIZADOS: AS PRÁTICAS INTEGRATIVAS COMO POSSIBILIDADES TERAPÊUTICAS
}

\section{CARE STORIES OF INSTITUTIONALIZED ELDERLIES: INTEGRATIVE PRACTICES AS THERAPEUTIC POSSIBILITIES}

\section{HISTORIAS DE CUIDADO ENTRE LOS ANCIANOS INSTITUCIONALIZADOS: PRÁCTICAS INTEGRADORAS COMO POSIBILIDADES TERAPÉUTICAS}

\author{
Alynne Mendonça Saraiva ${ }^{1}$ \\ Wilton Maravilha de Macedo e Silva ${ }^{2}$ \\ Jeferson Barbosa Silva ${ }^{3}$ \\ Priscilla Maria de Castro Silva ${ }^{4}$ \\ Maria Djair Dias ${ }^{5}$ \\ Maria de Oliveira Ferreira Filha ${ }^{6}$
}

Doi: $10.5902 / 2179769214211$

RESUMO: Objetivos: conhecer as histórias de cuidado e as implicações do uso da reflexologia podal em idosos. Método: pesquisa-ação, na qual foram realizadas sessões de reflexologia podal em idosos residentes em uma Instituição de Longa Permanência, situada no interior paraibano. A produção e análise das narrativas foram feitas de março a junho de 2012, através da história oral temática, que originou três eixos temáticos: As dores do corpo e da alma, Os chás e as massagens, O cuidado através dos pés. Resultados: dores difusas e dificuldades para dormir foram as principais queixas relatadas, para quais, os idosos utilizavam como recursos terapêuticos, os chás e as massagens. A realização da reflexologia além de permitir o alívio dos problemas mencionados, proporcionou bemestar, relaxamento, alívio da ansiedade e melhora na qualidade do sono. Considerações finais: as práticas integrativas possibilitam um cuidado integral ao idoso, pela facilidade de aplicação, promoção do relaxamento e bem-estar.

Descritores: Saúde do idoso; Instituição de longa permanência para idosos; Terapias complementares.

ABSTRACT: Aim: to understand the stories of care and the implications of using foot reflexology in the elderly. Method: action research, in which foot reflexology sessions were conducted in elderly residents of a long-stay institution located within Paraiba. The production and analysis of the narratives were made from March to June 2012, through thematic oral story, which originated three themes: The pains of body and soul, Teas and massages, Care through the feet. Results: diffuse pain and sleep difficulties were the

\footnotetext{
${ }^{1}$ Docente do Curso de Graduação em Enfermagem da Universidade Federal de Campina Grande-campus CuitéPB. Mestre em Enfermagem. Doutoranda do Programa de Pós Graduação de Enfermagem da Universidade Federal da Paraíba, João Pessoa, PB, Brasil. E-mail: alynneme@gmail.com

${ }^{2}$ Enfermeiro do Serviço de Atendimento Móvel de Urgência da cidade de Picuí, PB, Brasil. E-mail: wiltonmaravilha@hotmail.com

${ }^{3}$ Enfermeiro da Secretaria Municipal de Saúde de João Pessoa-PB. Mestrando do Programa de Pós Graduação de Enfermagem da Universidade Federal da Paraíba, João Pessoa, PB, Brasil. E-mail: jefersonbarbosa_@hotmail.com

${ }_{4}^{4}$ Docente do Curso de Graduação em Enfermagem da Universidade Federal de Campina Grande- PB. Mestre em Enfermagem. Doutoranda do Programa de Pós Graduação de Enfermagem da Universidade Federal da Paraíba, João Pessoa, PB, Brasil. E-mail: priscilamcs@hotmail.com

${ }^{5}$ Docentes do Programa de Pós Graduação em Enfermagem da Universidade Federal da Paraíba. João Pessoa, PB, Brasil. E-mail: mariadjair@yahoo.com.br

${ }^{6}$ Docentes do Programa de Pós Graduação em Enfermagem da Universidade Federal da Paraíba. João Pessoa, PB, Brasil. E-mail: marfilha@yahoo.com.br
} 


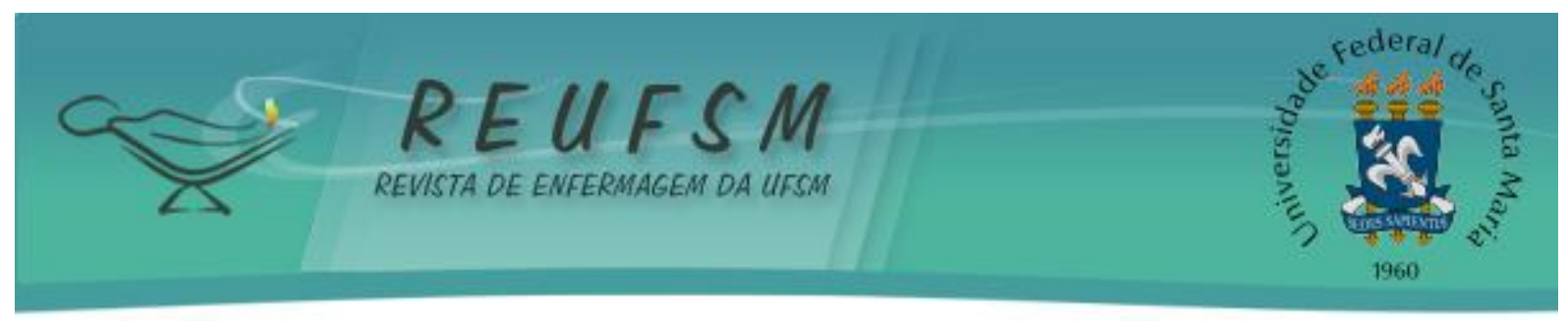

main complaints reported, for which the elderly used teas and massage as therapeuticresources. Besides alleviating the previously mentioned problems, the realization of reflexology provided well-being, relaxation, anxiety relief and improved quality of sleep. Final considerations: the integrative practices enable a comprehensive care to the elderly, since they are easy to apply and promote relaxation and well-being.

Descriptors: Health of the elderly; Homes for the aged; Complementary therapies.

RESUMEN: Objetivos: conocer las historias de cuidados y las implicaciones del uso de la reflexología podal en el anciano. Método: investigación-acción, en el que se llevaron a cabo sesiones de reflexología podal en ancianos residentes de una institución de larga permanencia ubicado en Paraiba (Brasil). La producción y el análisis de las narraciones se realizaron de marzo a junio de 2012, a través de la historia oral, originando tres ejes temáticos: El dolor de cuerpo y alma, infusiones y masajes, atención a través de los pies. Resultados: dolor difuso y dificultades para dormir fueron las principales quejas relatadas, para las cuales, las personas de edad utilizan como recursos terapéuticos, infusiones y masajes. La realización de la reflexología además de permitir el alivio de estos problemas, proporciona bienestar, relajación, alivio de la ansiedad y mejora la calidad del sueño. Consideraciones finales: las prácticas integradoras permiten una atención integral de los ancianos, por la facilidad de aplicación y la promoción de la relajación y el bienestar.

Descriptores: Salud del anciano; Hogares para ancianos; Terapias complementarias.

\section{INTRODUÇÃO}

O envelhecimento populacional é um fenômeno complexo que vem atingindo vários países e traz desafios constantes na busca por melhores condições de vida dos idosos. Abordar a temática do envelhecimento é ter a possibilidade de refletir sobre as necessidades de transformações sociais, políticas e econômicas que visem a inclusão dos idosos nas esferas sociais.

Em pesquisa realizada no Brasil, na década de 60 , a população com idade acima de 60 anos era estimada em 3 milhões de pessoas. Em 2008, esse número já chegava a 20 milhões, constatando um aumento de $700 \%$ em menos de 50 anos. Acredita-se ainda, que a cada ano, são incorporados 650 mil novos idosos na sociedade brasileira. ${ }^{1}$

Essa nova conjuntura social está afetando de maneira impactante vários setores da sociedade. No âmbito da saúde ela transcende os limites existentes, tanto por sua repercussão nos diversos níveis assistenciais, como pela demanda por recursos terapêuticos e estruturas organizacionais dos serviços. ${ }^{2}$

Deste modo, as políticas destinadas aos idosos precisam estar direcionadas à promoção da autonomia, a necessidade de cuidado e autossastifação e a capacidade física e mental desse grupo populacional. Além disso, devem favorecer a ressignificação da vida, incentivando ações inclusivas, de autocuidado e de atenção integral à saúde. ${ }^{1}$

Assim, o desenvolvimento de práticas de cuidados que possam amenizar os impactos sociais, físicos e psicológicos vivenciados pelo idoso, devem ser incentivadas, no intuito de promover uma melhor qualidade de vida para esse contingente populacional.

Neste cenário de produção de cuidados, as práticas integrativas e complementares vêm ganhando notoriedade como recursos terapêuticos voltados para a integralidade do ser. Essas práticas não se restringem apenas ao combate das doenças, mas proporcionam uma maior consciência corporal, valorização da subjetividade e autonomia dos sujeitos.

Como parte deste construto, em 2006, foi aprovada a Política Nacional de Práticas Integrativas e Complementares no Sistema Único de Saúde (SUS), que integra e legitima a 


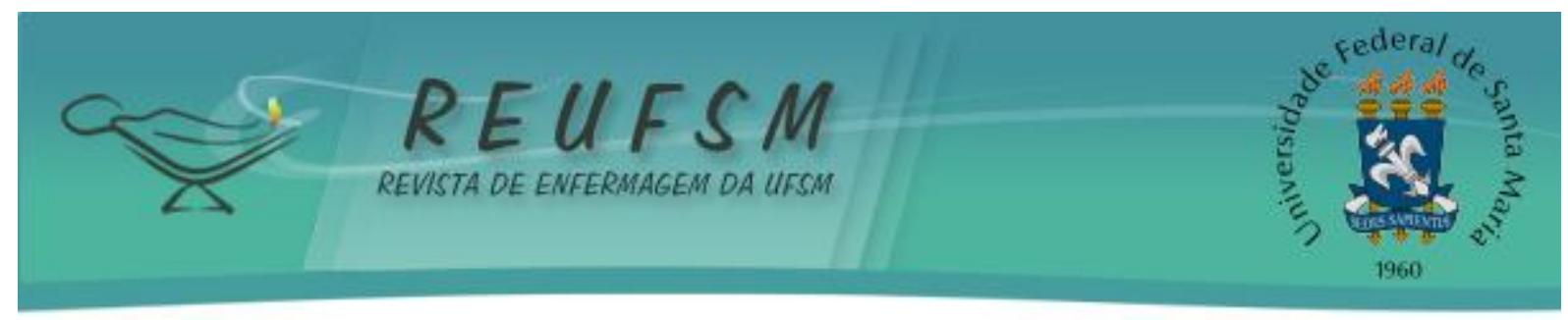

Acupuntura, Homeopatia, Fitoterapia, Medicina Antroposófica e Termalismo, como recursos terapêuticos a serem difundidos no SUS. ${ }^{3}$

No tocante à esta pesquisa, foi utilizada a reflexologia podal como uma prática integrativa e complementar de cuidado. Embora este recurso não esteja contemplado na Política acima citada, o mesmo vem sendo praticado em alguns serviços formais e informais de saúde, embasado na premissa da facilidade de sua utilização e aprendizagem. ${ }^{3}$

A reflexologia baseia-se em uma massagem na qual os pontos reflexos são pressionados, a fim de promover um estado de relaxamento profundo e estimular os processos curativos do próprio corpo. Essa técnica pode ser aplicada nos pés, não só porque neles passam os principais canais ou meridianos que conduzem a energia da força vital existente por todo o corpo humano, mas também, porque nos pés os reflexos são estimulados naturalmente, em virtude de permanecerem muito tempo sob a pressão do peso corpóreo estático ou dinâmico. ${ }^{4}$

A reflexologia, assim como outras práticas integrativas, pode estar sendo utilizada de maneira concomitante aos recursos alopáticos. Além disso, pode favorecer o envelhecimento ativo, propiciando ao idoso um conhecimento maior do seu corpo, uma interação com sua espiritualidade, valorização da autoestima e do autocuidado.

É necessário ampliar conhecimentos e discussões sobre a reflexologia e outras práticas integrativas no cuidado com os idosos, uma vez que os profissionais de saúde devem buscar compreender as dimensões que abrangem a integralidade do cuidar através de outras possibilidades terapêuticas, que possam promover o bem-estar, estreitar o vínculo profissional-idoso e favorecer a autonomia.

Portanto, o objetivo principal deste trabalho é conhecer as histórias de cuidado e as implicações do uso da reflexologia podal em idosos, e teve como objetivos específicos: conhecer as principais queixas dos idosos; revelar os recursos utilizados para melhorar a saúde e conhecer as implicações do uso da reflexologia podal em idosos.

\section{MÉTODO}

Por se tratar de um estudo que discute a temática do envelhecimento e consequentemente envolve várias dimensões desse processo, optou-se por uma abordagem plurimetodológica, utilizando a pesquisa ação e a história oral como técnicas de pesquisa. A pesquisa-ação estimula a participação das pessoas envolvidas na pesquisa e abre o seu universo de respostas, passando pelas condições de trabalho e vida da comunidade, buscando as explicações dos próprios participantes. ${ }^{5}$

As pesquisas em História Oral podem ser divididas em História Oral de vida, História Oral temática, História Oral testemunhal e Tradição Oral. Neste estudo, foi utilizada a História oral temática, pois se trata da produção de narrativas breves sobre um acontecimento específico. A História Oral temática é definida então, como um relato de experiências pessoais de indivíduos, que tenham características comuns, relativos a acontecimentos ou fatos significativos e constitutivos de sua experiência vivida. ${ }^{6}$

As narrativas foram construídas com base nas experiências dos idosos durante a realização de sessões de reflexologia podal, duas vezes por semana, no turno da manhã, por um período de dois meses.

Este estudo está vinculado ao projeto de pesquisa intitulado "Práticas de cuidado na rede formal e informal de saúde", aprovado no Comitê de Ética em Pesquisa/CCS/UFPB, sob $\mathrm{n}^{\circ}$. de protocolo: 0059. Para manter o anonimato dos participantes foram criados pseudônimos com nomes de pássaros. 


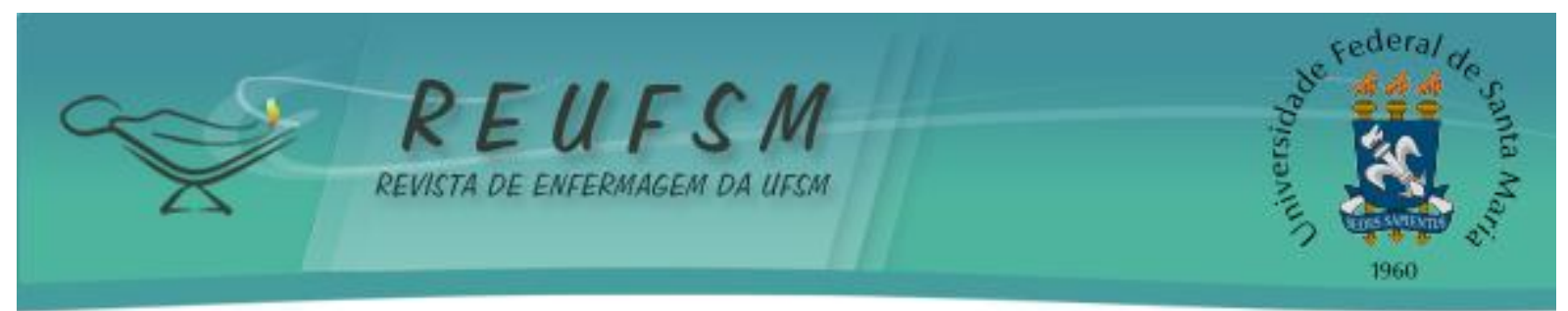

A Instituição de Longa Permanência para Idosos (ILPI) "Casa da Vó Filomena”, cenário desta pesquisa, está situada no município de Cuité-PB. Este local foi escolhido, pois se constitui como único espaço público voltado para o acolhimento de idosos na cidade. 0 fato de ser campo de estágio da Universidade favoreceu o desenvolvimento da pesquisa, pois já havia um conhecimento prévio sobre o cotidiano dos idosos que lá residem.

0 estudo foi realizado no período de março a junho de 2012. No fim de março houve a visita a instituição para conhecer os idosos que poderiam participar da pesquisa. A aplicação da reflexologia se deu nos meses de abril e maio de 2012. No mês junho foram coletadas as narrativas, para serem transcritas, textualizadas e transcriadas. Posteriormente, as versões finais foram apresentadas aos idosos para que os mesmos pudessem ter conhecimento e autorizar as histórias.

Embora no momento da pesquisa, houvessem 20 idosos na instituição, ao utilizar a técnica da História oral temática para captação das narrativas, a escolha dos colaboradores ocorreu por meio dos seguintes critérios de inclusão: estar consciente e disposto a aceitar a realização da reflexologia; não possuir nenhum problema circulatório ou dermatológico que afetasse os membros inferiores. Pelo fato, da maioria dos idosos abrigados na instituição possuir doenças graves e incapacitantes, como demência e Alzheimer, além de problemas locomotores, apenas três idosos estavam em condições físicas e psíquicas e aceitaram participar da pesquisa.

0 presente estudo tem como foco principal o relato das experiências dos idosos a partir da realização de reflexologia podal. Nas pesquisas que envolvem a história oral, a quantidade de colaboradores não constitui um empecilho ou fragilidade, já que a principal finalidade é enfatizar a singularidade das experiências vivenciadas. Para conduzir as narrativas, foram feitas 3 perguntas: Conte-me o que aflige sua saúde; Que recursos o(a) senhor(a) utiliza para melhorar sua saúde, quanto se sente doente? Conte-me o que você sentiu após as sessões de reflexologia.

A discussão do material empírico foi feita através da análise temática, na qual foram criados 3 eixos temáticos: As dores do corpo e da alma; Os chás e as massagens; 0 cuidado através dos pés, que permitiram a reunião e organização do material. Durante a interpretação do material, foi necessário ter atenção ao referencial relacionado à investigação, pois ele deu o embasamento e as perspectivas significativas para o estudo.

\section{RESULTADOS E DISCUSSÃO}

Os idosos colaboradores da pesquisa moravam há mais de cinco meses na instituição e tinham idade acima de 70 anos. Os questionamentos que conduziram as narrativas visavam descobrir as principais queixas apresentadas pelos idosos, e o que eles utilizavam para melhorar a saúde, nesse sentido foi construído o primeiro eixo temático.

\section{As dores do corpo e da alma}

Através das narrativas, pode-se revelar o que afligia a saúde física e mental dos idosos, descrita nos seguintes relatos:

As vezes eu sinto dificuldade pra dormir, acordo assim meio esmuricido [...] as vezes sinto uma dorzinha nas costas, mais nada muito grande não. (Senhor Canário)

[...] minha pressão é baixa [...] Insônia eu sinto demais! E tem hora que fico meio estressada mesmo. Quando é pra dormir, eu tomo um 


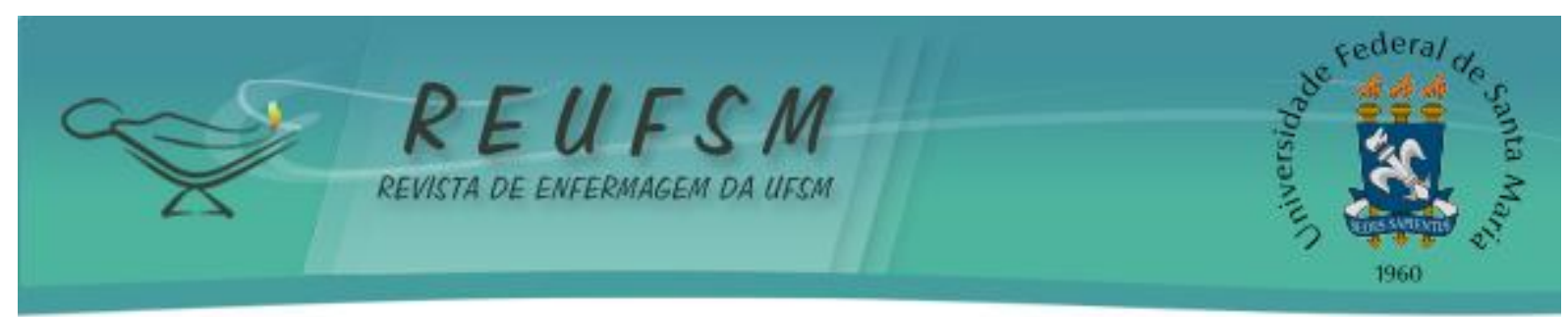

Diazepan, e quando é problema de estresse, apenas de conversar com uma pessoa eu já fico melhor! Hoje eu tô com uma dor nos braços e nas pernas. Aí eu já tomei uns remédios, mas continuo sentindo as dores. (Senhora Andorinha)

Eu sinto dor na coluna já faz muito tempo! $E$ as vezes sinto difculdades para dormir [...] ai tem uma medicação que eu tomo, que é o Gardenal, mas gosto dessas coisas não, porque sei que me ofende. Eu pego a receita do médico e compro, e quando não compro eu pego lá no posto. (Senhora Bem-te-vi)

Dentre as aflições relatadas pelos colaboradores, observou-se que a dificuldade para dormir, constitui o principal sofrimento dos idosos, seguida pela dor e pelo estresse.

Em estudo realizado sobre a qualidade do sono com 38 idosos institucionalizados na cidade de São Paulo, mostrou que mais da metade dos pesquisados apresentou sono de má qualidade. Foi observado que os idosos com menos de cinco anos de institucionalização, tinham o sono mais prejudicado quando comparados com aqueles institucionalizados há mais de cinco anos. Acredita-se que a deterioração do ciclo sono-vigília pode estar relacionada às mudanças de estilo de vida do idoso após a institucionalização. ${ }^{7}$

É sabido que o sono de um idoso difere do sono de um adulto jovem, primordialmente, pelo maior número de interrupções como também de uma diminuição na profundidade do sono, podendo estes casos de insônia estarem ou não relacionados a quadros de depressão, ansiedade, estresse e neurose, ou serem agravados pelo uso excessivo ou incorretos de medicamentos. ${ }^{8}$

A dor foi outra queixa presente nas narrativas dos colaboradores. A dor corporal pode estar associada a diversos motivos, tais como: sofrimento prolongado, transtornos psiquiátricos, inexistência de tratamento ou até abuso de medicamentos, tornando-se um problema para o idoso e seus familiares. A alta prevalência de dor em idosos está geralmente associada a desordens crônicas, particularmente à doenças músculo esqueléticas, como artrites e osteoporose. ${ }^{9}$

Pesquisas comprovam que, cerca de $85 \%$ dos indivíduos com mais de 65 anos apresentam, pelo menos, um problema significativo de saúde que os predisponham à dor. A dor é frequente em $32 \%$ a $34 \%$ dos idosos, ocasional em $20 \%$ a $25 \%$, aguda em $6 \%$ a $7 \%$ e crônica em $48 \%$ a $55 \%{ }^{10}$

Além disso, a dor pode ou não estar relacionada à dificuldade para dormir, relatada pelos idosos. Porém, é possível dizer que uma condição interfere diretamente na outra, levando muitas vezes o indivíduo a buscar recursos medicamentosos para aliviar os sintomas, como visto nas narrativas a utilização de psicotrópicos para dormir. No entanto, é importante ressaltar que os idosos apresentam uma maior vulnerabilidade aos eventos adversos relacionados a esses tipos de medicamentos. ${ }^{10}$

0 desânimo e estresse evidenciado nos relatos dos colaboradores é uma condição comumente encontrada em pesquisas sobre o envelhecimento. Em estudo realizado, com idosos no município de João Pessoa, percebeu que o estresse constitui uma das principais queixas desse grupo populacional. As autoras do estudo observaram que a exclusão social, geralmente vivenciada pelos idosos, a desvalorização e abandono familiar e as alterações físicas decorrentes do próprio envelhecimento, constituem fatores determinantes para a presença do estresse. ${ }^{11}$

A situação torna-se ainda mais grave se levarmos em consideração a situação dos residentes em instituições de longa permanência. Estes, que no mínimo encontram-se separados do seu ambiente familiar habitual, cercados de pessoas estranhas e muitas vezes 


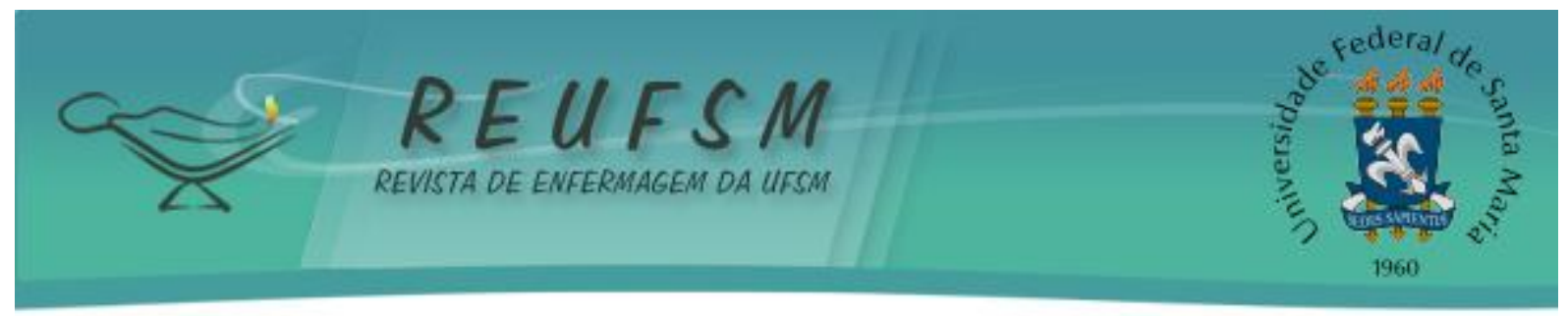

isolados da sociedade em que viveram durante anos, podem experimentar a difícil e desgastante sensação de abandono, dependência e inutilidade. ${ }^{8}$

Nesta perspectiva, o isolamento social pode levá-los à perda de identidade, de liberdade, de autoestima, solidão e, muitas vezes, recusa da própria vida, o que justifica a alta incidência de doenças mentais nos asilos. A baixa qualidade de vida oferecida pela maior parte das instituições, também contribui para o agravamento do estado efetivo dos idosos levando, muitas vezes, a estados depressivos graves. ${ }^{12}$

Quando indagados sobre que recursos terapêuticos eles utilizam para melhorar a saúde, além dos medicamentos, foi referido o uso de plantas medicinais e massagens, como demonstram os relatos da categoria a seguir.

\section{Os chás e as massagens}

O uso de plantas medicinais na forma de chás é bastante comum entre os idosos, conforme narraram os colaboradores.

Uso chá. As vezes melhora alguma coisa. No tempo que eu tava com desinteria, comi muito mastruz. (Senhor Canário)

As vezes eu faço massagem, peço pra menina pegar um óleo e fazer em mim. Já fiz massagem nos pés também, e eu já tomo chá normalmente porque eu não tomo café, aí tomo chá, de cidreira, de erva-doce, qualquer chá eu tomo. (Senhora Bem-te-vi)

Neste relato, além do uso de plantas medicinais, a idosa refere que já fez alongamento:

Tomo muito mastruz e a partir disso eu melhorei. Já tomei chá de camomila também. Massagem eu nunca fiz, mas já fiz alguns tipos de alongamento [...] ah, e usei óleo de copaíba. (Senhora Andorinha)

De acordo com Organização Mundial de Saúde (OMS) cerca de 65 a $80 \%$ da população mundial não têm acesso ao atendimento primário de saúde e recorre à medicina tradicional, especialmente às plantas medicinais, na procura de alívio para muitas doenças. ${ }^{13}$

As plantas medicinais são opções frequentemente utilizadas na busca de soluções terapêuticas, principalmente pela população de menor poder aquisitivo, tornando-se uma alternativa barata, eficiente e culturalmente difundida. Torna-se cada dia mais comum escutar relatos de idosos que referem o uso de preparados a base de plantas no momento das consultas de enfermagem. ${ }^{14}$

Nas narrativas dos idosos observou-se a utilização da planta conhecida popularmente como Mastruz (Chenopodiumambrosioides). $\mathrm{O}$ uso de suas folhas e sumidades florais é conhecido no tratamento de afecções pulmonares e das vias aéreas e indicado em casos de gripe. ${ }^{15}$

Outra planta medicinal utilizada, comumente conhecida como Erva-doce (PimpinellaanisumL.), geralmente é preparada na forma de chá e é indicada em casos de dor abdominal, flatulência e febre. Destaca-se também o uso da Erva-cidreira (Lippia $a l b a)$, na preparação de chás, é indicada em casos de dor abdominal e vômitos. ${ }^{16}$

A Camomila (Matricariachamomilla L.) também referenciada nas narrativas, pode ser considerada uma das plantas mais utilizadas pela população, além de ser extremamente popular pelos seus efeitos calmantes. 0 chá de camomila ainda possui indicação em casos de problemas digestivos e intestinais, dores no estômago e é considerado um ótimo remédio natural em casos de inflamação. ${ }^{15}$ 


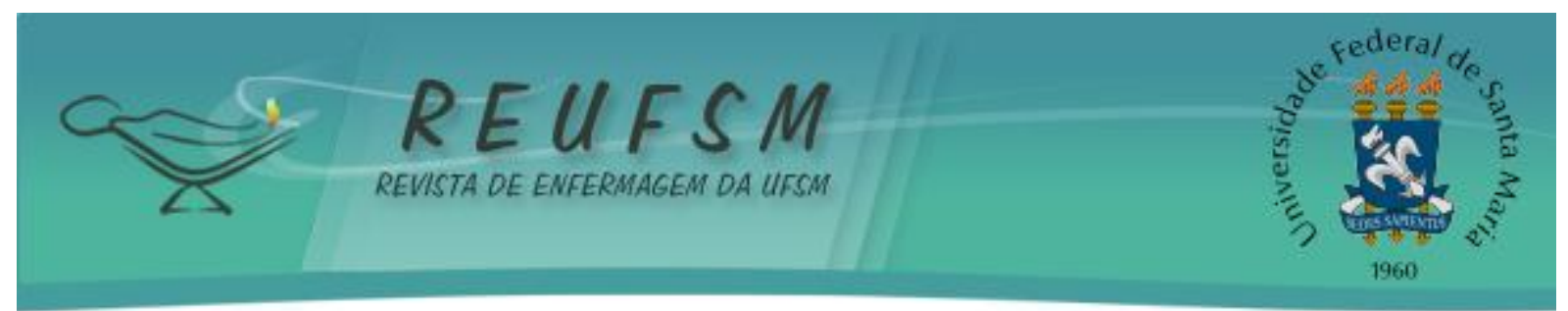

Com relação à massagem, esta vem sendo utilizada como recurso terapêutico bastante adotado para a prevenção de doenças e para o alívio de dores que podem ser de causa psicológica ou física. Tem como principal intuito, tornar o indivíduo consciente do seu corpo, das suas tensões, da sua respiração e das suas cargas emocionais, bem como melhorar a nutrição dos tecidos através do aumento da circulação sanguínea e linfática. ${ }^{17}$

A sensação do toque, promovida pela massagem, é essencial para o bem-estar dos idosos, pois, além das mudanças fisiológicas que ocorrem no organismo, atua de modo a melhorar o estado psicológico, favorecendo uma maior segurança e confiança e aumentando autoestima. O toque constitui-se então em uma forma de comunicação e expressão do sentimento. ${ }^{18}$

Além da massagem, a realização do alongamento é uma atividade que pode trazer benefícios a saúde. $O$ alongamento, além de minimizar as degenerações naturais do envelhecimento, contribui na geração de força na musculatura e diminui indiretamente a frequência de quedas, fazendo com que o idoso se mantenha produtivo e independente. ${ }^{19}$

Após realizar a massagem da reflexologia, foi questionado aos colaboradores quais as sensações experienciadas após as sessões. Com base nas narrativas, foi criado o terceiro eixo.

\section{0 cuidado através dos pés}

Embora, no momento que foi questionada sobre as principais queixas que afligiam a saúde, uma colaboradora não tivesse relatado nenhum agravo ou doença que causasse irritação nas pernas, quando indagada a respeito das sensações obtidas através da técnica de reflexologia, obteve-se a seguinte resposta:

Achei bom não é?, gostei! Me senti melhor! Teve uma melhora na minha dor na perna [...] Com relação ao sono não, mas acho que gera melhorias na minha vida sim, acho que quando fazemos a massagem melhora principalmente meu problema de ansiedade. (Senhora Andorinha)

A reflexologia podal, que tem como base a realização de massagens em pontos reflexos dos pés, pode apresentar vários benefícios corporais ${ }^{4}$, como também aliviar 0 sofrimento psíquico advindo da depressão, da ansiedade e da angústia.

As massagens, em qualquer parte do corpo, são consideradas como técnicas de relaxamento, e quando realizadas em idosos permitem sensações de bem-estar e descanso, além de diminuir as tensões musculares, promovendo alívio, tranquilidade e amenizando a ansiedade e o nervosismo. ${ }^{17}$

Os relatos abaixo mostram que além das dores físicas, a reflexologia permitiu uma melhora nas condições de sono e repouso, além da promoção de vínculo, interatividade no cotidiano desses idosos.

Achei boa a massagem! Ótima! Realmente tive uma melhora depois que comecei essa massagem nos pés! Eu me sentia bem no dia que fazia essa massagem. De noite eu durmo bem e os dias que eu não fiz, senti mais dor na minha perna. Quando faço essa massagem nos pés, me sinto bem melhor, não tenho dor. Sinto um bem estar, sinto que durmo melhor, pois com esta dor na perna que descobri no começo do ano, não estava mais conseguindo dormir bem. (Senhora Bem-te-vi) 


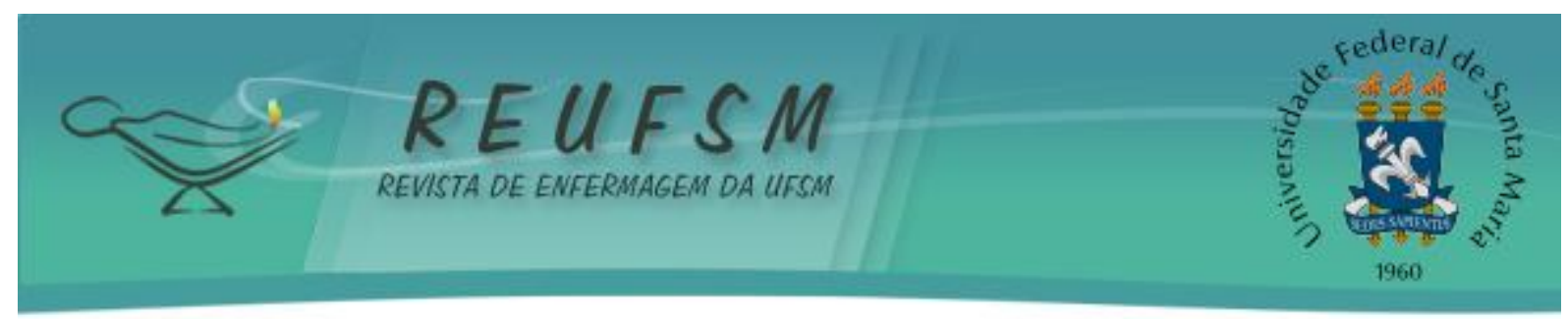

Eu acho bom quando faço essas massagens nas pernas! Me fazem bem viu? Eu tenho estado bem melhor, as vezes ainda preciso comprar uns remédios mas, eu tenho me sentido bem. Antes eu ia dormir era quase de madrugada, depois dessas massagens nos pés, acabou-se esse problema! Hoje em dia eu durmo muito! Até as dores que eu sentia antigamente acabou-se, porque as vezes doía um pouquinho as pernas e os pés, mas agora isso acabou-se. (Senhor Canário)

A massagem traz à pele sensações táteis multiplicadas intermitentes, ritmadas e repetidas. As mãos passando de região em região abrange todas as terminações do tato, e estas impressões táteis acabam por lançar nos centros nervosos um influxo muito grande, sendo considerado uma espécie de recarga nos nervos, ocorrendo assim, à sensação de bem estar. ${ }^{20}$

A realização das massagens nos pés tornou-se a cada dia um momento também de diálogo e desabafo por parte dos idosos. Os temas das conversas variavam bastante, incluíam suas alegrias e peripécias vividas no passado, os problemas familiares, melhoras nas condições de saúde, rotinas diárias, assim como também relatavam suas preocupações e anseios dos dias atuais.

Durante a aplicação da reflexologia, nenhum dos idosos relatou dor, mal-estar ou qualquer outro desconforto que pudesse estar relacionado à massagem nos pés. As sessões, geralmente, eram momentos prazerosos de relaxamento, diálogo e partilha.

Pode-se constatar efeitos positivos na saúde dos idosos, através do uso de chás, alongamento e durante a realização da reflexologia. A enfermagem, por estar em constante mudança, buscando seu aprimoramento na arte do cuidar, pode desenvolver e incentivar atividades e ideias que tornem possível a busca por novas formas de cuidado e que possibilitem uma visão integral do idoso.

\section{CONSIDERAÇÕES FINAIS}

A pesquisa mostrou que o desenvolvimento da reflexologia podal em idosos, possuiu além de uma grande aceitação, um alívio das principais queixas que foram relatadas nas entrevistas. Os idosos envolvidos na pesquisa relataram o conforto gerado pelo diminuição das dores que vinham sentindo, possibilitando-os a sensação de bem estar, tornando seu dia muito mais produtivo.

Quanto ao problema de dificuldade para dormir, observou-se nos relatos obtidos, uma grande melhora desse quadro. 0 idoso ao ter uma qualidade no seu ciclo de sono/vigília, torna-se mais bem humorado e comunicativo, além de diminuir consideravelmente o hábito de utilizar-se da automedicação para combater a insônia.

Durante o desenvolvimento das sessões de reflexologia, observou-se não apenas a promoção de relaxamento, mas também que os idosos necessitavam de afeto e atenção. A institucionalização para muitos idosos gera isolamento, solidão e carência afetiva, podendo também culminar em quadros de estresse e ansiedade.

Os momentos de interação proporcionados pela prática da massagem nos pés tornaram-se ocasiões propícias para a partilha de experiências, escuta qualificada e estreitamento do vínculo entre o terapeuta e o idoso. Nesse sentido, o relacionamento interpessoal, proporcionou momentos singulares e essenciais no processo de cuidar.

Assim, é importante que os profissionais de saúde, que atuam promovendo cuidado aos idosos, estejam dispostos a conhecer e praticar outras estratégias de cuidado que possibilitem a minimização de efeitos colaterais, permita a interação e formação de vínculos com os idosos e proporcionem uma melhor qualidade de vida. 


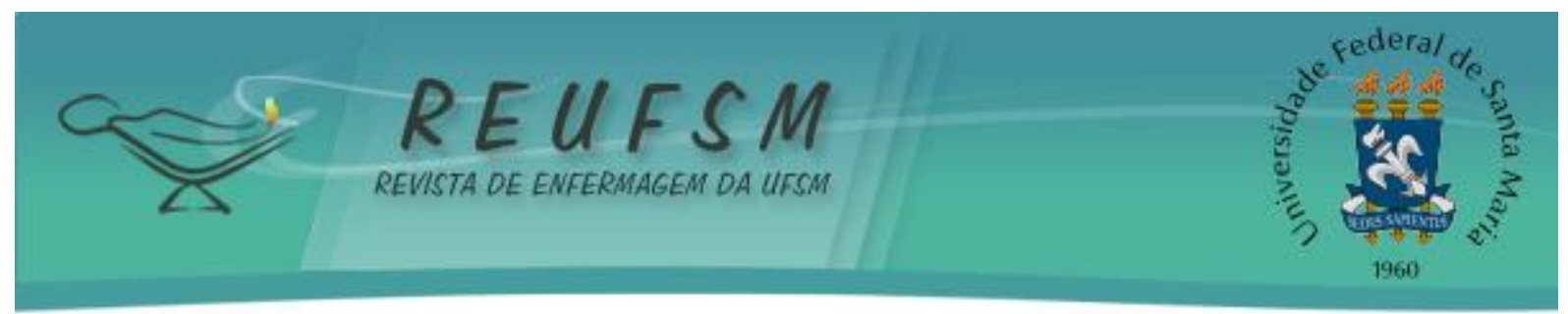

\section{REFERÊNCIAS}

1. Veras R. Envelhecimento populacional contemporâneo: demandas, desafios e inovações. Rev Saúde Pública, 2009;43(3):548-54.

2. Pereira RJ, Cotta RMM, Franceschini SCC, Ribeiro RCL, Sampaio RF, Priore SE, et al. Contribuição dos domínios físico, social, psicológico e ambiental para a qualidade de vida global de idosos. RevPsiquiatr Rio Gd Sul [Internet]. 2006 [acesso em 2012 maio 31];28(1):27-38. Disponível http: / / www.scielo.br/scielo.php?script=sci_arttext\&pid=S0101$81082006000100005 \&$ ing $=$ en.

3. Brasil. Ministério da Saúde. Secretaria de Atenção à Saúde. Política Nacional de Práticas e Complementares no SUS: atitude de ampliação de acesso [Internet]. 2006 [acesso em 2011 set 23]. Disponível em: http://bvsms.saude.gov.br/bvs/publicacoes/pnpic.pdf.

4. Lourenço OT. Reflexologia podal: sua saúde através dos pés. $2^{a}$ ed. Rio de Janeiro: GroundLtda; 2002.

5. Melo Neto JF. Pesquisa-ação: aspectos práticos da pesquisa-ação nos movimentos sociais populares e em extensão popular [Internet]. Universidade Federal da Paraíba; [acesso em 2012 ago 11]. Disponível em: http://www.prac.ufpb.br/copac/extelar/producao_academica/artigos/pa_a_pesquisa_aca o.pdf.

6. Meihy JCSB, Holanda F. História oral: como fazer, como pensar. $2^{\mathrm{a}}$ ed. São Paulo: Contexto; 2011. 175 p.

7. Araújo CLO, Ceolim MF. Qualidade do sono de idosos residentes em instituição de longa permanência. RevEscEnferm USP. 2010;44(3):619-26.

8. Souza JC, Magna LA, Paula LH. Insônia e o uso de hipnóticos em idosos institucionalizados. RevPpsiquiatrClín (São Paulo)[Internet]. 2002 [acesso em 2012 jul 12];29(5):216-27. Disponível em: http://hcnet.usp.br/ipq/revista/vol29/n5/216.html.

9. Andrade FA, Pereira LV, Sousa FAEF. Mensuração da dor no idoso: uma revisão. RevLatinoamEnferm [Internet]. 2006 [acesso em 2012 jul 17];14(2):271-6. Disponível em: http: / / www.scielo.br/scielo.php?script=sci_arttext\&pid=S0104-

$11692006000200018 \& \operatorname{lng}=$ en\&nrm=iso\&tlng=pt.

10. Dellaroza MSG, Furuya RK, Cabrera MAS, Matsuo T, Trelha C, Yamada KM, et al. Caracterização da dor crônica e métodos analgésicos utilizados por idosos da comunidade. AMB Rev Assoc MedBras[Internet]. 2008 [acesso em 2012 jun 12];54(1):36-41. Disponível em: http://www.scielo.br/pdf/ramb/v54n1/18.pdf.

11. Rocha IA, Braga LAV, Tavares LM, Andrade FB, Ferreira Filha MO, Dias MD, et al. A terapia comunitária como um novo instrumento de cuidado para saúde mental do idoso. RevBrasEnferm. 2009;62(5):687-94.

12. Martins RM. A depressão no idoso. Spectrum [Internet]. 2004 [acesso em 2012 jul 14];119-24. Disponível em: http://www.ipv.pt/millenium/millenium34/9.pdf.

13. Organização Mundial da Saúde. Estratégia de la OMS sobre a medicina tradicional 20022005. Genebra: OMS; 2002. 


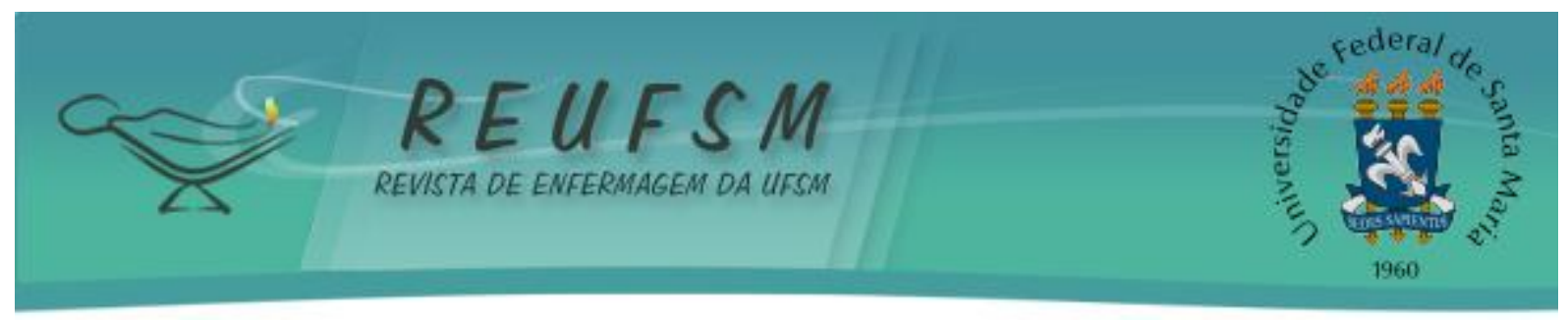

14. Oliveira CJ, Araújo TL. Plantas medicinais: usos e crenças de idosos portadores de hipertensão arterial. Rev Eletrônica Enferm [Internet]. 2007 [acesso em 2012 maio 15];9(1):93-105. Disponível em: http://www.fen.ufg.br/revista/v9/n1/v9n1a07.htm.

15. França ISX, Souza JA, Baptista RS, Brito VRS. Medicina popular: benefícios e malefícios das plantas medicinais. Brasília. RevBrasEnferm. 2008;61(2):201-8.

16. Torres AR, Oliveira RAG, Diniz MFFM, Araújo EC. Estudo sobre o uso de plantas medicinais em crianças hospitalizadas da cidade de João Pessoa: riscos e benefícios. RevBrasFarmacogn. 2005:15(4):373-80.

17. Seubert F, Veronese L. A massagem terapêutica auxiliando na prevenção e tratamento das doenças físicas e psicológicas. In: Anais do XIII Encontro Paranaense, VIII Congresso Brasileiro, II Convenção Brasil/Latino-América de Psicoterapias Corporais; 2008 maio 22-24; Curitiba: Centro Reichiano de Psicologia Corporal. CD-ROM. [ISBN - 978-85-87691-13-2]. Disponível em: http://www.centroreichiano.com.br/artigos/Anais\%202008/Fabiano\%20e\%20Liane.pdf.

18. Santos $M M O$, Sandoval JMH. O toque como estratégia comunicativa de promoção do bem-estar: percepções de idosos institucionalizados. In: VI Conferência Brasileira de Comunicação e Saúde; 2003 out 1-3; São Paulo: Universidade Metodista de São Paulo; 2003 [acesso em 2012 ago 23]. Disponível em: http://encipecom.metodista.br/mediawiki/images/4/45/O_toque_como_estrategia__Maria_e_Maximiliano.pdf.

19. Souza RM. O efeito agudo do alongamento na marcha dos idosos. Rev Eletrônica Unibrasil [Internet]. 2008 [acesso em 2012 ago 23];1(1). Disponível em: http://revista.unibrasil.com.br/index.php/retdu/article/view/34.

20. Silva RNN, Oliveira EN. O brotar da massoterapia em Sobral: uma experiência singular [monografia]. Sobral: Universidade do Vale do Acaraú; 2004. 59 p.

Data de recebimento: 02/06/2014

Data de aceite: 26/02/2015

Contato do autor responsável: Alynne Mendonça Saraiva

Endereço postal: Rua Enfermeira Ana Maria Barbosa n 114, apt 402. Jardim Cidade Universitária. João Pessoa-PB, Brasil. CEP 58052-270

E-mail: alynneme@gmail.com 